\title{
EXPERIMENTAL INVESTIGATION OF ICE ACCRETION ON HORIZONTAL AXIS WIND TURBINES
}

\author{
M.A. Elhajare, K. Pope, X. Duan \\ Department of Mechanical Engineering, \\ Memorial University of Newfoundland \\ St. John's, Canada
}

\begin{abstract}
In this paper, ice accretion on a wind turbine blade with a NACA 63415 airfoil is investigated with experimental techniques. Several different angles of attack, from $0^{\circ}$ to $90^{\circ}$, and wind velocities, $3 \mathrm{~m} / \mathrm{s}, 4 \mathrm{~m} / \mathrm{s}$ and $5 \mathrm{~m} / \mathrm{s}$ are studied. Tests are conducted in a climatic wind chamber with a fan and two spray nozzles. The largest quantity of ice accumulation on the blade was $7.2 \mathrm{~kg}$, at an angle of attack of $90^{\circ}$. The results of this paper provide valuable new experimental data for ice accretion on wind turbine blades.
\end{abstract}

Keywords-Wind turbines; ice accretion; wind tunnel

\section{INTRODUCTION}

In northern locations, ice is a significant obstacle for efficient operation of wind turbines. From measurements by Natural Resource's Canada, ice accretion can occur up to $20 \%$ of the time, between November and April [1]. Several problems for wind power are caused by ice accretion, including reduced power output due to disrupted aerodynamics, overload due to delayed stall, and increased fatigue of components due to imbalance of the ice load [2]. Ice accretion on a wind turbine occurs when super cooled liquid water droplets in fog, clouds or rain collide with a turbine and freeze on the surface.

To predict the annual power production for a wind turbine in northern locations, the wind and ice conditions must be considered [3]. Power output losses were estimated from 17\% to $30 \%$ for wind turbine operating in locations that are affected by ice accumulation [4-6]. Ice accumulation changes with variations of the atmospheric temperature and water droplet size [2]. Better predictive techniques and experimental data are needed to predict ice accretion on wind turbine blades [7]. The external conditions at a cold climate site have several effects on wind turbine behaviour and on the efficiency of a wind farm.

Ice accumulation on a wind turbine blade causes distortion to the blades profile, which can impede the aerodynamic efficiency of an airfoil. The distortion frequently does not depend on the amount of ice accretion but on the location that accrues it; a small amount of ice accretion on the leading edge of a blade can significantly impair the aerodynamic performance. Additionally, ice accretion can cause wind turbine vibration, which can increase fatigue loads and cause structural failure [8].

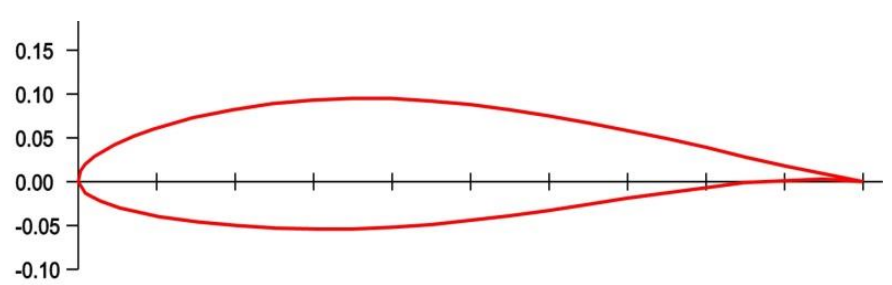

Figure 1. NACA 415-63 blade airfoil (NASA, 2014).

During icing conditions, a wind turbine is often shut-down to prevent damage caused by the ice accumulation. In this paper, experiments are conducted on a non-rotating wind turbine blade (NACA 415-63 airfoil (Fig. 1)). This research will focus on two important aspects of ice accumulation on non-rotating wind turbine blades, including (i) the quantity and (ii) location of ice accumulation.

\section{EXPERIMENTAL METHODOLGY}

In this section, details of the experimental setup used to study ice accretion on non-rotating wind turbine blades is presented. As illustrated in Fig. 2, a wind turbine blade of 0.93 m length, with a chord length of $19 \mathrm{~cm}$ at the root to $8.3 \mathrm{~cm}$ at the tip is manufactured for the experiments. The blade is made by carbon fiber. During the experiments, the thickness and chord of the blade are measured at four points (Tip, Mid1, Mid2, Root) six times (each $30 \mathrm{~min}$ ). A digital caliper is used to measure the thickness of ice and a digital scale to measure the mass of ice.

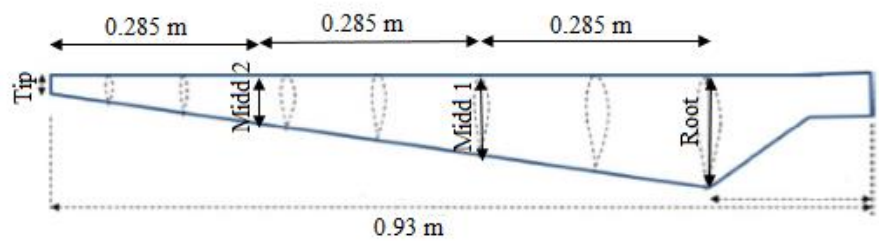

Figure 2. Schematic of wind turbine blade. 


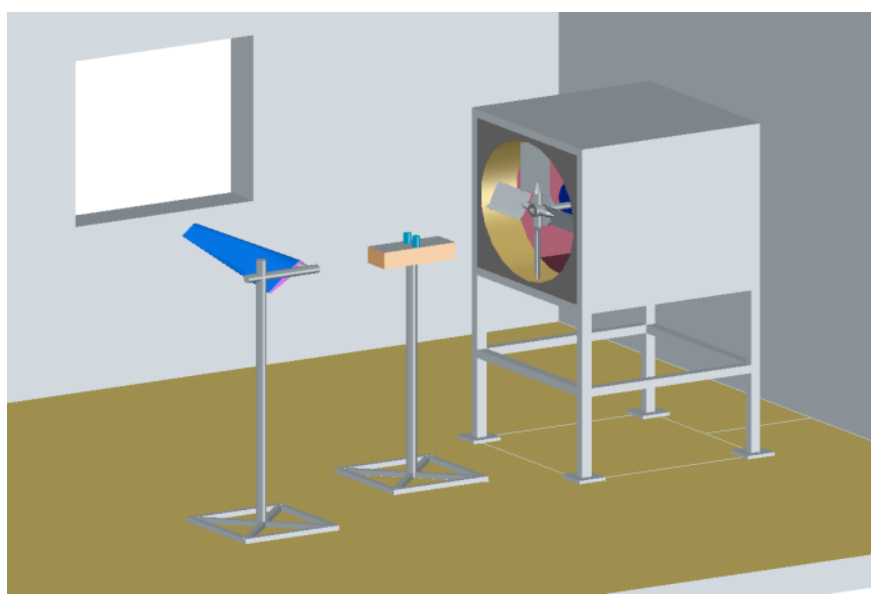

Figure 3. Schematic of experimental setup.

The experiments are conducted in a cold chamber with dimensions of $7.6 \mathrm{~m}, 4.6 \mathrm{~m}$, and $4.6 \mathrm{~m}$. The cold chamber is climatically controlled to allow sub-zero temperatures $\left(-10{ }^{\circ} \mathrm{C}\right.$ in this paper). As illustrated in Fig. 3, two FullJet spray nozzles are placed between the fan and the wind turbine blade. The wind velocity (V) is maintained at $3.5 \mathrm{~m} / \mathrm{s}, 4 \mathrm{~m} / \mathrm{s}$ and $5 \mathrm{~m} / \mathrm{s}$. The positions of the blade and spray nozzle from the fan are $(1.5 \mathrm{~m}, 0.502 \mathrm{~m}, 0.835 \mathrm{~m})$ and $(0.833 \mathrm{~m}, 0.485 \mathrm{~m}, 0.321 \mathrm{~m})$, respectively. All coordinates are taken from the bottom left edge of the front side of the fan.

\section{RESULTS AND DISCUSSION}

In this section, new experimental results on wind turbine blade icing are presented. As presented in Table 1, 7 different experiments are conducted with different wind velocities and angle of attacks $(\alpha)$. Wind velocities from $3.5 \mathrm{~m} / \mathrm{s}$ to $5 \mathrm{~m} / \mathrm{s}$ are investigated for a $45^{\circ}$ angle of attack and angle of attacks from $0^{\circ}$ to $90^{\circ}$ are investigated for a wind velocity of $5 \mathrm{~m} / \mathrm{s}$. In all tests, the wind turbine blade has a horizontal angular position (Fig. 4). The liquid water content (LWC) is 0.6 and the mean volume diameter of the spray is $50 \mu \mathrm{m}$. All experiments are conducted for 3 hours.

\begin{tabular}{|c|c|} 
Table 1. Parameters of experiments \\
\hline $\begin{array}{c}\text { Velocity } \\
(\mathrm{m} / \mathrm{s})\end{array}$ & $\begin{array}{c}\text { Angle of attack } \\
\left({ }^{\circ}\right)\end{array}$ \\
\hline 5 & $0^{\circ}$ \\
5 & $30^{\circ}$ \\
5 & $45^{\circ}$ \\
5 & $60^{\circ}$ \\
5 & $90^{\circ}$ \\
4 & $45^{\circ}$ \\
3.5 & $45^{\circ}$ \\
\hline
\end{tabular}

As illustrated in Fig. 4, the thickness of ice on the wind turbine blade is measured every 30 minutes during the 3 -hour test. Two different measurements (chord and width) are taken at four location of the blade span (Fig. 2). The chord length is measured before the tests, at each location, and then it is measured again with ice accumulation. The difference in the two measurements represents the thickness of ice on the leading and trailing edge (chord thickness of ice), which is plotted in Fig. 4a. As presented in Fig. 4, the majority of ice on the chord is at the leading edge. This is noteworthy as ice buildup on the leading edge can cause significant deterioration of aerodynamic performance [9]. The width ice thickness, represents the thickness of ice perpendicular to the chord and is plotted in Figure 4b. The results plotted in Figure 4 are for a wind velocity of $5 \mathrm{~m} / \mathrm{s}$ and an angle of attack of $45^{\circ}$. The transient results of other tests follow similar trends.

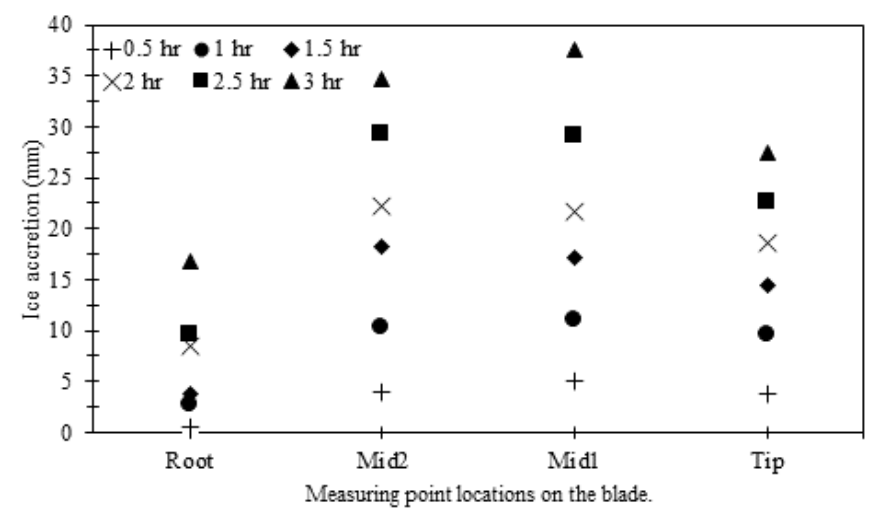

(a)

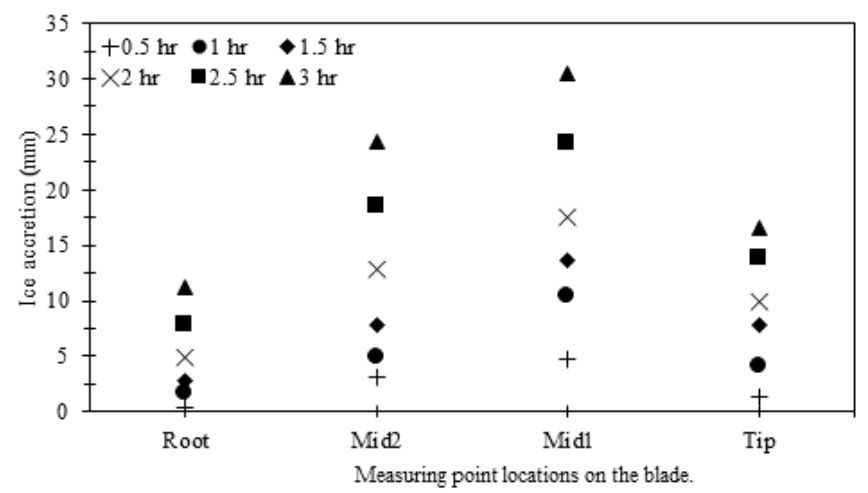

(b)

Figure 5. Transient ice accretion for $\mathrm{V}=5 \mathrm{~m} / \mathrm{s}$ and $\alpha=45^{\circ}$ on the (a) chord and (b) width of a wind turbine blade

As illustrated in Fig. 5, significant ice accretes on the leading edge of the wind turbine blade. Comparing Figs. 4 and $5 \mathrm{a}$, over $30 \mathrm{~mm}$ ice thickness is accreted on the leading edge, in the middle section. The root has the smallest thickness of ice, which is approximately half as thick as in the middle of the blade. The blade's tip also has significant leading edge ice accumulation, which is more than $25 \mathrm{~mm}$ thick.

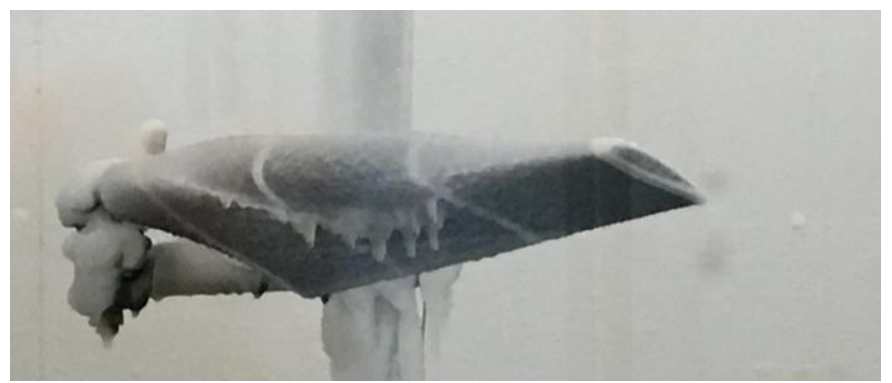

Figure 5. Ice accretion on a wind turbine blade at $\mathrm{V}=5 \mathrm{~m} / \mathrm{s}$ and $\alpha=45^{\circ}$ after 3 hours of icing conditions. 


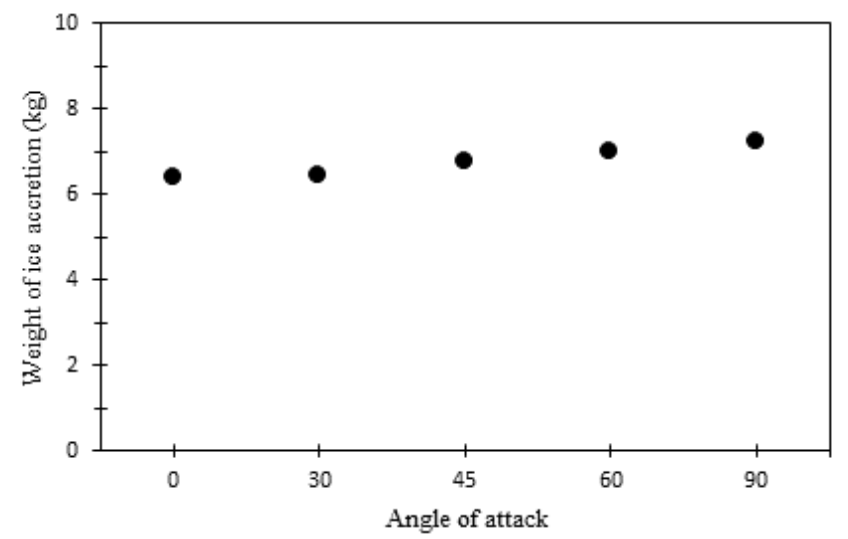

Figure 6. Weight of ice accreted on a wind turbine positioned at different angle of attacks for a wind velocity of $5 \mathrm{~m} / \mathrm{s}$.

As illustrated in Figure 6, the total quantity of ice that accretes on a non-rotating wind turbine blade is affected by the blade's angle of attack. At an angle of attack of $0^{\circ}$, the total ice accumulation is approximately $6.5 \mathrm{~kg}$, which increases to 7.2 $\mathrm{kg}$ at an angle of attack of $90^{\circ}$. The results of Fig. 6 suggest that angle of attack of a non-rotating wind turbine blade can affect the quantity of ice accretion. For conditions that are causing ice accretion, the position of the blade can be altered to help reduce the quantity of accumulated ice on the blade which can help reduce the amount of time the turbine is unable to be operated. However, when the angle of attack is low, the quantity of ice accumulation on the leading edge is higher than for a blade at $90^{\circ}$, despite more total ice accumulating on a blade at $90^{\circ}$.

In Figure 7 , the quantity of ice accretion on the wind turbine blade for different wind velocities are presented. The increase in ice accretion is nearly linear with respect to wind speed. In the conditions of these experiments, the ice accretion quantity increased from approximately $3.45 \mathrm{~kg}$ at $3.5 \mathrm{~m} / \mathrm{s}$ to $4.92 \mathrm{~kg}$ at 5 $\mathrm{m} / \mathrm{s}$.

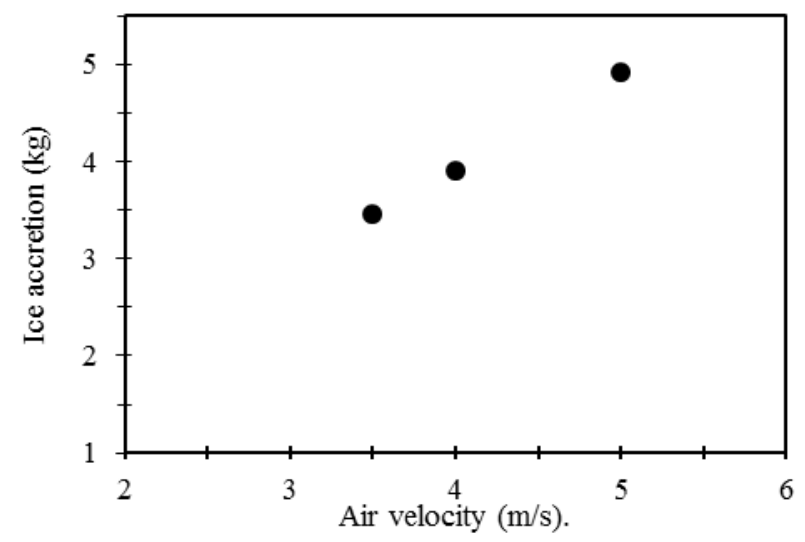

Figure 6. Weight of ice accreted on a wind turbine positioned at an angle of attack of $45^{\circ}$ in different wind velocities.

\section{CONCLUSIONS}

This paper studied the accumulation of ice on a wind turbine blade. The study was conducted for five different angles of attack $\left(0^{\circ}\right.$ to $\left.90^{\circ}\right)$ and three speeds of wind $(3.5 \mathrm{~m} / \mathrm{s}, 4$ $\mathrm{m} / \mathrm{s}$ and $5 \mathrm{~m} / \mathrm{s}$ ). The temperature was maintained at $-10{ }^{\circ} \mathrm{C}$ with a LWC of $0.6 \mathrm{~g} / \mathrm{m}^{3}$. The largest accumulation of ice was at 5 $\mathrm{m} / \mathrm{s}$, with the blade at $45^{\circ}$. More ice accretion occurred for higher angles of attack, however, more ice accumulated on the leading edge at lower angles of attack. The results also indicated a linear relationship between ice accumulation and wind velocity. The results of this paper provide new experimental data and insights for ice accretion on a wind turbine blade that has twist and varied chord length along the blade span.

\section{ACKNOWLEDGMENTS}

The authors gratefully acknowledge the financial support of the Research and Development Corporation of Newfoundland and Labrador and the Libyan Ministry of Higher Education and Scientific Research.

\section{REFERENCES}

[1] Canada Wind Energy Association. (2015). Wind energy market Installed capacity.

[2] Homola, M.C., Nicklasson, P.J., Sundsbo, P.A., Virk, M.S., Wallenius, T., 2010. Effect of atmospheric temperature and droplet size variation on ice accretion of wind turbine blades. Journal of Wind Engineering and Industrial Aerodynamics.

[3] Tammelin, B. and Seifert, H. (2001). Large wind turbines go into cold climate regions. In EWEC 2001. Copenhagen.

[4] Barber, S., Wang, Y., Chokani, N., and Abhari, R. S. (2009). The effect of ice shapes on wind turbine performance. In 13th Int. Workshop on Atmospheric Icing, Andermatt, Switzerland.

[5] Øyvind Byrkjedal. (2009). Estimating wind power production loss due to icing. In 13th Int. Workshop on Atmospheric Icing, Andermatt, Switzerland.

[6] Homola, M. C., Ronsten, G., and Nicklasson, P. J. (2009). Energy production losses due to iced blades and instruments at Nygardsfjell, Sveg and Aapua. In 13th International workshop on Atmospheric Icing.

[7] Fikke, S. (2006). Cost 727-Atmospheric icing on structures; measurement and data collection on icing. State of the Art. MeteoSwiss.

[8] Alsabagh, A., Tiu, W., Xu, Y., \& Virk, M. (2013). A Review of the Effects of Ice Accretion on the Structural Behavior of Wind Turbines. Wind Engineering, 37(1), 59-70.

[9] Ibrahim, G.M., Pope, K., and Muzychka, Y.S. (2018) Effects of blade design on ice accretion for horizontal axis wind turbines. Journal of Wind Engineering and Industrial Aerodynamics 173: 39-52. 